Book Review

\title{
Review of Stories of Open: Opening Peer Review Through Narrative Inquiry
}

Emily Rogers, Valdosta State University

\section{ABSTRACT}

Review of Ford, E. (2021). Stories of open: Opening peer review through narrative inquiry. Association of College and Research Libraries.

\section{KEYWORDS}

peer review, journal publishing, narrative inquiry

\section{SUGGESTED CITATION}

Rogers, e. (2022). Review of Stories of open: Opening peer review through narrative inquiry. Journal of New Librarianship, 7(1), 69-72. https://doi.org/10.33011/newlibs/11/7

This is an Open Access article distributed under the terms of the Creative Commons Attribution 4.0 International License (http://creativecommons.org/licenses/by/4.0), which permits unrestricted use, distribution, and reproduction in any medium, provided the original work is properly cited. 
The limitations of traditional methods of peer review in the journal article publishing industry are evident from decades of anecdotal experiences of scholars and authors across the academic disciplines. In Stories of open: Opening peer review through narrative inquiry, Emily Ford critiques both the traditional methods of the peer review system but also explores newer, more open, and transparent pathways to developing and publishing scholarship. Her investigation centers upon the stories shared by her ten research participants, using narrative inquiry as the methodology. Through the process of "storying stories," she gathers and analyzes the experiences of authors, editors, and peer reviewers-roles the participants take on at different junctures-as they investigate open alternatives to the closed peer review publication process.

Positive attitudes toward openness are widespread in the library and information science discipline, most commonly toward open access publishing and open educational resources. These issues earn some discussion within Ford's book, but within the context of the ethical and social implications of openness more generally, particularly as applied to peer review. Open peer review occurs when both author(s) and reviewer(s) are named. Currently, few journals and publishers in LIS allow open peer review, though some experimentation is occurring. Even when in place, open peer review often receives skeptical glances from the larger scholarly community, including tenure and promotion review boards.

Ford's purpose is "to capture, make sense of, and disseminate human stories related to peer review and open peer review in LIS" (p. 14). After an introductory chapter about narrative inquiry as a qualitative methodology and a feminist, exploratory approach to raising questions about its subject matter, the book continues with stories of peer review and current practice in LIS. Ford views the interviews more as conversations that try to eliminate the domination of interviewer over interviewee 
and cites bell hooks' pedagogy of hope and love as a means of connecting these participants. In Chapter 8 Ford presents the "Storying Stories" Transcript Analysis Process, in which "reviewers critically examine interview transcripts, asking where participants resist and challenge cultural norms, as well as how they accommodate them" (p. 159). The author employs various fonts and formats to present her own exposition, excerpts from interviews, and then her own replies, allowing opportunity for conversation and responses. Personal reflection questions at the end of each chapter invite the reader to participate in these ongoing conversations.

What are the benefits of open peer review? Ford sees the openness as vital for increasing opportunities for scholarly conversations and improving works in progress. Indeed, "the power and dominance of traditional notions of publishing and institutional structures can impede the growth and evolution of publishing practices" (33). Traditional peer review practices increase the vulnerability of authors and the invisibility of editors and reviewers, whereas open peer review could change the quality of what gets published as well as the transparency, says Ford as she advocates for valuesdriven publishing. This book recognizes the very real pressures of publication for tenure and promotion but looks further to the creative and collaborative opportunities that open peer review can offer.

What some readers will find most valuable, though, in this investigation is the chance to view firsthand the stories other authors, editors, and reviewers have to tell. Writing, editing, and publishing can be lonely occupations, even for coauthors, and the author notes several times that librarians often receive less training for their scholarly writing and publishing roles than do many other scholars. Through this valuable volume, librarians who write and publish can see how other writing librarians work to establish their identities as authors. Useful for people interested in the research and writing 
processes, the book may be its most compelling when it addresses the questions how do we create what we publish? - and how can we make those products and processes more fulfilling? 